\title{
Administration of unmodified prolactin (U-PRL) and a molecular mimic of phosphorylated prolactin (PP-PRL) during rat pregnancy provides evidence that the U-PRL:PP-PRL ratio is crucial to the normal development of pup tissues
}

\author{
L Yang, C B Kuo, Y Liu, D Coss, X Xu, C Chen, \\ M L Oster-Granite and A M Walker
}

Division of Biomedical Sciences, University of California, Riverside, California 92521, USA

(Requests for offprints should be addressed to A M Walker; Email: ameae.walker@ucr.edu)

\begin{abstract}
During rat pregnancy initial high concentrations of prolactin (PRL) decline by about day 9, concomitant with an increase in the ratio of unmodified to phosphorylated PRL. The physiological significance of both the decline in total PRL and the change in ratio of the two PRLs is unknown. To test the importance of each, either unmodified PRL (U-PRL) or a molecular mimic of phosphorylated PRL (PP-PRL) were continuously administered to rats throughout pregnancy. A dose of $6 \mu \mathrm{g} / 24 \mathrm{~h}$ resulted in circulating concentrations of $50 \mathrm{ng} / \mathrm{ml}$ of each administered PRL and had little effect on the pregnancy itself. After birth, pups were killed and various tissues examined. In the pup lungs, exposure to additional PP-PRL caused a reduction in epithelial integrity and an increase in apoptosis, whereas exposure to additional U-PRL had beneficial, anti-apoptotic effects. In the heart, PP-PRL caused an apparent developmental delay, whereas U-PRL promoted tissue compaction. In the blood, U-PRL increased the number of mature red blood cells at the expense of white blood cell production. Within the white blood cell population, myelopoiesis was favored at the
\end{abstract}

expense of lymphopoiesis. PP-PRL, in contrast, had a less dramatic influence on the hematopoietic compartment by promoting red blood cell maturation and granulocyte production. In the thymus, exposure to PP-PRL caused accumulation of apoptotic thymocytes in enlarged glands, whereas exposure to U-PRL resulted in smaller thymi. In the spleen, exposure to U-PRL increased cellularity, with the majority of cells belonging to the erythroid series - a finding consistent with increased red blood cells in the circulation. Exposure to PP-PRL was without discernible effect. In all of these tissues, the contrasting effects of the two PRLs indicate that the absolute concentration of PRL is not crucial, but that the ratio of U-PRL to PP-PRL has a profound effect on tissue development. In brown fat, both PRL preparations decreased the number of lipid droplets. This result is therefore probably a consequence of the increase in total PRL. The results of this study attest to the importance of the U-PRL:PP-PRL ratio normally present during pregnancy and have provided clues as to the possible pathogenesis of a variety of neonatal problems. Journal of Endocrinology (2001) 168, 227-238

\section{Introduction}

Prolactin (PRL) is secreted from the anterior pituitary either as an unmodified polypeptide or as a posttranslationally modified form of the hormone (reviewed in Sinha 1995). The possible posttranslational modifications are many, including glycosylation (Lewis et al. 1984), phosphorylation (Oetting et al. 1986, Brooks et al. 1990, Aramburo et al. 1992) and proteolytic cleavage (Oetting \& Walker 1985, Sinha et al. 1985, Clapp 1987). This laboratory has focused its attention on the biology of phosphorylated PRL (Ho et al. 1989, 1993a,b, Greenan et al. 1989, Wang \& Walker 1993, Wang et al. 1996, Chen et al. 1998), a form of posttranslationally modified PRL that occurs in all species thus far examined (Oetting et al. 1986, Brooks et al. 1990, Aramburo et al. 1992, Chen et al. 1998).

In the rat, phosphorylation of PRL is quantitatively the most important posttranslational modification (Greenan et al. 1989, Ho et al. 1993a,b, Wang \& Walker 1993). Previous studies have documented reproducible changes in the ratio of unmodified to phosphorylated PRL that are produced by the pituitary during the estrus cycle (Ho et al. 1993a), pregnancy and pseudopregnancy (Ho et al. 1993b). High ratios of unmodified to phosphorylated PRL, for example, are representative of the PRL released 
during mid and late rat pregnancy, during the proestrus afternoon surge and in response to estrogen treatment of ovariectomized animals (Ho et al. 1993a,b).

In vitro, in three very different cell systems, unmodified PRL has been shown to promote cell proliferation and phosphorylated PRL has been shown to antagonize this activity (Ho et al. 1989, Krown et al. 1992, Wang \& Walker 1993, Chen et al. 1998). However, when the function of PRL is not proliferative, the phosphorylated PRL may be an equal or better agonist than unmodified PRL (Kuo et al. 2000).

Circulating PRL is at its highest concentration at the beginning of pregnancy and pseudopregnancy, but the percentage of phosphorylated PRL is also relatively high at this time (Ho et al. 1993b). It is when the level of circulating PRL decreases to pre-mating values at about day 9 that there is a major decrease in the proportion that is phosphorylated (Ho et al. 1993b). Administration of additional phosphorylated or unmodified PRL during pregnancy should, therefore, illustrate the physiological importance of the reduction in PRL in addition to the physiological importance of this compositional change.

The present study has demonstrated that changes in the ratio of unmodified to phosphorylated PRL in the maternal circulation, produced via administration of recombinant unmodified PRL (U-PRL) or pseudophosphorylated PRL (PP-PRL) have a marked influence on the development of a number of fetal tissues; tissues previously shown by others to express high levels of PRL receptors (Royster et al. 1995, Freemark et al. 1995, 1997, Brown-Borg et al. 1996, Tzeng \& Linzer 1997).

\section{Materials and Methods}

Analysis of the effect of in vivo administration of phosphorylated PRL requires the use of a recombinant molecular mimic that cannot be dephosphorylated during the experiment. We have previously produced such a mimic by substitution of the serine, which is phosphorylated in PRL secretory granules (Wang et al. 1996), by an aspartate residue to produce S179D PRL (Chen et al. 1998). This molecular mimic of phosphorylated PRL, referred to as pseudophosphorylated PRL (PP-PRL), cannot be dephosphorylated, as it contains no phosphate group. It has previously been shown to reproduce the antagonism of unmodified PRL (U-PRL) with a potency similar to that of the naturally phosphorylated molecule (Wang \& Walker 1993, Chen et al. 1998). U-PRL utilized in the experiments was also produced by recombinant technology. As both proteins were expressed in Escherichia coli, they have no posttranslational modifications. The recombinant U-PRL has also been extensively analyzed for biological activity and found to have greater $\mathrm{Nb} 2$ proliferative activity than hormone extracted from pituitaries (Chen et al. 1998).

\section{Protein expression}

Both recombinant proteins were produced and characterized as previously described (Chen et al. 1998). Both proteins for the study were expressed and purified in parallel and were expressed at similar levels (Chen et al. 1998). The recombinant PRLs were then tested for proliferative activity in the $\mathrm{Nb} 2$ bioassay, or antagonism of this (Chen et al. 1998), as appropriate. Recombinant PRL preparations were concentrated in saline using Amicon Centripreps (Amicon, Danvers, MA, USA).

\section{Animal experiments}

Preliminary In preliminary experiments, both short-term clearance and steady-state concentrations after implantation of an osmotic minipump were analyzed. Both experiments used ${ }^{35}$ S-biosynthetically-labeled recombinant proteins. Briefly, induction of U-PRL or PP-PRL expression was performed with the E. coli suspended in $\left[{ }^{35} \mathrm{~S}\right]$ methioninesupplemented methionine-free minimum essential medium (Sigma Chemical Co., St Louis, MO, USA). Specific activity was determined by a combination of scintillation spectrometry and gel electrophoresis compared against standards. Using $100 \mu \mathrm{Ci} / \mathrm{ml}\left[{ }^{35} \mathrm{~S}\right]$ methionine, specific activities of between 0.5 and $1.4 \times 10^{5}$ c.p.m. $/ \mu \mathrm{g}$ PRL were obtained for different batches. Full biological activity of the radiolabeled material was ascertained by $\mathrm{Nb} 2$ bioassay (conducted as described in Chen et al. 1998).

For assessment of steady-state concentrations after administration, samples were concentrated to either $0 \cdot 3$ or $1 \mu \mathrm{g} / \mu \mathrm{l}$ saline and then used to fill Alzet osmotic minipumps (Alza, Palo Alto, CA, USA). After implantation of the minipumps subcutaneously in pregnant animals, samples of blood were obtained from the tail at intervals for 16 days. In a separate experiment, samples were taken only on day 19.5 of pregnancy. Immunoprecipitation with excess anti-hPRL antibody (NIDDK IC5, AFP55781789; Dr A F Parlow, Torrane, CA, USA) and protein A-agarose ensured maximal precipitation from blood samples so that the percentage of counts still in the PRLs could be determined.

For short-term clearance, female rats at the same stage of the estrous cycle (assessed by vaginal smear analysis) were injected intraperitoneally with bromocryptine $(500 \mu \mathrm{g} / \mathrm{kg}$ $2 \mathrm{~h}$ before cannulation) to reduce endogenous PRL release. Cannulae were placed in both external jugular veins under pentobarbital anesthesia $(45 \mathrm{mg} / \mathrm{kg})$. Radiolabeled U-PRL or PP-PRL was injected as a bolus of $750 \mathrm{ng}$ in $300 \mu \mathrm{l}$ saline containing $0 \cdot 05 \%$ bovine serum albumin. Collection of blood samples $(\sim 300 \mu \mathrm{l})$ was from the opposite cannula into heparinized tubes. Plasma was prepared and $100 \mu \mathrm{l}$ samples were used for scintillation spectrometry.

Pup development Virgin female Sprague-Dawley rats (Harlan Laboratories, San Diego, CA, USA) weighing 
240-260 g were housed under constant conditions of $12 \mathrm{~h}$ light : $12 \mathrm{~h}$ darkness and given free access to laboratory chow and water. After mating and observation of a vaginal plug, they were randomly assigned to three different groups, to be treated with U-PRL, no PRL or the molecular mimic of phosphorylated PRL (PP-PRL). Alzet minipumps (model 2004), containing the appropriate PRL, were implanted under local anesthesia the morning after observation of a vaginal plug. Pumps delivered $6 \mu \mathrm{g}$ $\mathrm{PRL} / 24 \mathrm{~h}$ per rat. Ten rats were assigned to each group. Rats were weighed every other day as a measure of normal health and food consumption. On day 17.5 of gestation, they were moved to individual cages in preparation for pup delivery.

On day 6.5 of gestation (counting day 0 as the evening of mating and day 0.5 as the time of pump implantation), blood samples were obtained from the tail between 0900 and $1200 \mathrm{~h}$.

In the morning, after delivery of the pups, the animals were observed and the pups separated, weighed and killed by an overdose of metafane (Mallinkrodt, Mundelein, IL, USA). Two representative pups from each litter were fixed in periodate-lysine-paraformalde fixative (McLean \& Nakane 1974) and the remainder were used either as donors of trunk blood or for analysis of organ sizes/weights or cellularity. Sizes were assessed in situ using a micrometer and weights were determined after dissection and removal of extraneous connective tissue. Spleen cellularity was assessed by teasing the contents into culture medium. Mature red blood cells were then lysed by resuspension in 0.017 M Tris containing 0.144 $\mathrm{M} \mathrm{NH}_{4} \mathrm{Cl}, \mathrm{pH} 7 \cdot 4$ before the remaining cells were counted with a hemocytometer.

Twenty hours after removal of the pups, the dams were killed by decapitation under low stress conditions and the uteri were examined for implantation sites.

All animal procedures were approved by the University of California, Riverside committee on laboratory animal care and were in accordance with NIH guidelines.

\section{Histological processing}

Some blood samples were used to assess packed red cell volume. Others were used to prepare smears that were subsequently fixed in methanol and stained with Giemsa. A differential white blood cell count was then performed.

Tissues from the fixed animals were dissected, dehydrated in a graded ethanol series and embedded in paraplast. Sections were cut at a thickness of $6 \mu \mathrm{m}$ and stained with hematoxylin and eosin. The heart, lung and thymus were dissected and processed as a unit to enable orientation of the left and right heart and lung after sectioning. Adipose tissue was removed from the interscapular region. Tissue from each fixed pup was sectioned and, after analysis, representative images were chosen for presentation.

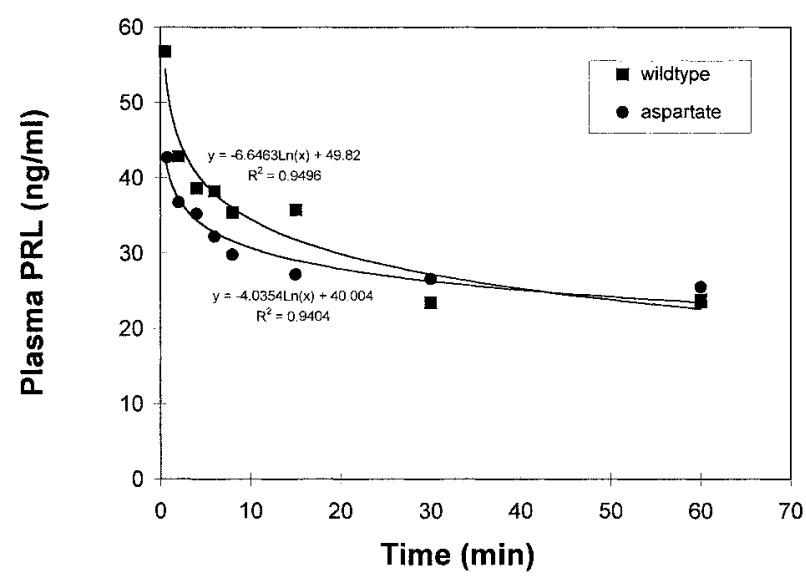

Figure 1 Short-term clearance of U-PRL and PP-PRL from the circulation. A bolus of $750 \mathrm{ng}$ radiolabeled PRL was infused as described under Materials and Methods. Blood samples were obtained at the times indicated and the concentration of administered PRL calculated from the specific activity. The graph shows the result from one animal given U-PRL (wildtype) and one given PP-PRL (aspartate), but each is representative of 10 replicates. Both animals were in estrus, as determined by vaginal smear analysis.

\section{Detection of apoptosis}

Apoptosis was detected on tissue sections using ApopTag reagents marketed by Intergen (Purchase, NY, USA). Briefly, these reagents modify endonuclease-cleaved genomic DNA using terminal deoxynucleotidyl transferase. The deoxynucleotidyl transferase adds digoxigeninlabeled nucleotides which, once incorporated, are recognized by fluorescently-labeled anti-digoxigenin antibodies.

\section{Progesterone assay}

After preparation of plasma from the day 6.5 blood samples, progesterone concentrations were assayed by radioimmunoassay (Diagnostic Products coat-a-count progesterone assay, Los Angeles, CA, USA). All samples were measured in the same assay.

\section{Results}

\section{Clearance}

Figure 1 shows the results of the short-term clearance assay. Both forms of PRL left the circulation at very similar rates. Most movement out of the circulation is due to simple dilution into the extracellular tissue fluids and is not a receptor-mediated event. Ten minutes after administration of the bolus, amounts in the circulation almost leveled off, with a very slow decline thereafter. The concentration at which this slow decline began was dependent on the stage of the estrous cycle (other stages of 


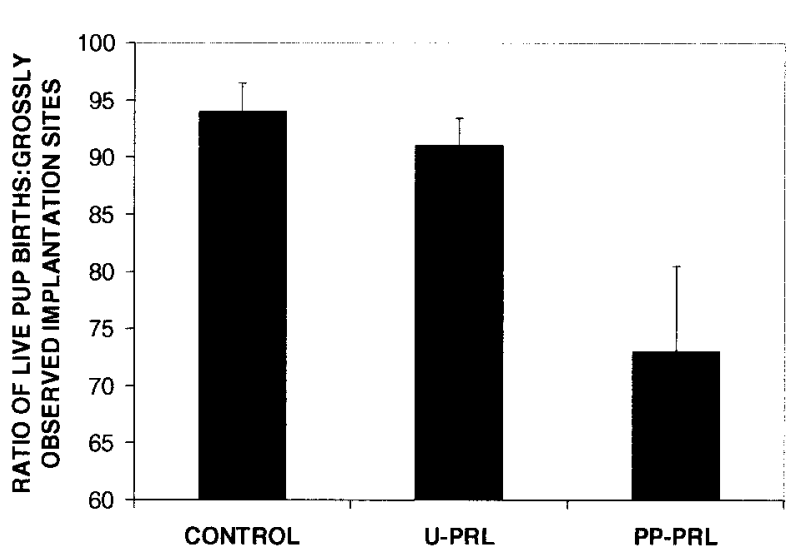

Figure 2 Ratio of live pup births to grossly observed implantation sites. The bars represent the means \pm S.E.M. U-PRL, unmodified prolactin; PP-PRL, the molecular mimic of phosphorylated prolactin.

the estrous cycle not shown), but was the same for both PRLs at an equivalent stage.

Both PRLs achieved equivalent steady-state levels by day 3-4 after pump implantation. The concentration of circulating administered PRL was directly proportional to the amount delivered by the pump and placement of either prolactin in concentrations of $1 \mathrm{mg} / \mathrm{ml}$ into an osmotic minipump delivering $6 \mu \mathrm{g} / 24 \mathrm{~h}$, resulted in a circulating concentration of $50 \mathrm{ng} / \mathrm{ml}$ plasma by day 4 of pregnancy (data not shown).

\section{General observations}

Figure 2 illustrates the ratio of live pups to grossly obvious implantation sites evident when the mothers were killed 1 day after giving birth. As these are grossly obvious implantation sites, the data are in no way affected by problems with initial implantation and therefore represent the survival of pups from well-established implantations. As can be seen, PP-PRL decreased pup survival in utero or within $8 \mathrm{~h}$ of birth. The number of delivered, dead pups is given in Table 1 and the remainder of the difference was produced by resorption in utero. In contrast, administration of U-PRL had no effect on in utero or post-delivery pup survival. As a consequence of reduced in utero pup survival, average litter weights were reduced in the PP-PRLtreated groups, but the average pup weight was not different from either no PRL treatment or treatment with U-PRL (Table 1). Treatment with either the PP-PRL or the U-PRL had no effect on the duration of pregnancy (Table 1). When delivered, however, the pups derived from PP-PRL-treated animals looked premature compared with those in the untreated group, and the pups from the U-PRL-treated mothers had the external appearance of 1- or 2-day-old pups. These differences were most evident in the texture and color of the skin. PP-PRLexposed pups had extremely transparent and fragile skin, whereas U-PRL-exposed pups had thicker, pinker and far less transparent skin than the controls (data not illustrated). Also noted in the PP-PRL-treated mothers were decreased nest-building and pup retrieval activities compared with the other two groups, plus absent placentophagia in two of eight mothers.

\section{Postmortem examination and histological analysis}

Only those pups that survived until the designated time of killing were examined further. This was to exclude effects of tissue autolysis from the histological examination.

Lungs Gross examination showed the left lung of PP-PRL-exposed pups to be smaller than those in the control or U-PRL-exposed pups. Histological examination of both the right and left lung showed fairly normal alveolar development, but a breakdown in epithelial integrity. This was most severe in the left lung. Figure 3 compares equivalent views of the more intact upper right lung lobes from control (B, E and H), PP-PRL-exposed (C, F and I) and U-PRL-exposed (A, D and G) pups. Some epithelial damage can be attributed to tissue processing, but the major effect of PP-PRL exposure on epithelial

Table 1 General observations of U-PRL- and PP-PRL-treated dams. Values are number or mean \pm S.E.M.

\begin{tabular}{|c|c|c|c|}
\hline & Control & U-PRL-treated & PP-PRL-treated \\
\hline Female rats pregnant to term & 7 & 7 & 8 \\
\hline Duration of pregnancy & Normal & Normal & Normal \\
\hline Average implantation sites per animal & $14 \pm 1$ & $13 \pm 1$ & $13 \pm 1$ \\
\hline Total pups delivered & 90 & 89 & 83 \\
\hline Average litter size & $13 \pm 1$ & $13 \pm 1$ & $10 \pm 1$ \\
\hline Average litter weight $(\mathrm{g})$ & $84 \cdot 9 \pm 5 \cdot 3$ & $82 \cdot 2 \pm 8 \cdot 8$ & $69 \cdot 8 \pm 9 \cdot 1$ \\
\hline Average pup weight (g) & $6 \cdot 6 \pm 0 \cdot 1$ & $6 \cdot 5 \pm 0 \cdot 1$ & $6 \cdot 7 \pm 0 \cdot 1$ \\
\hline Dead pups* & 2 & 2 & 11 \\
\hline Progesterone at day $6.5(\mathrm{ng} / \mathrm{ml})$ & $311 \pm 26$ & $268 \pm 19$ & $282 \pm 21$ \\
\hline
\end{tabular}

${ }^{*} \mathrm{At}$, or within $8 \mathrm{~h}$ of delivery. 

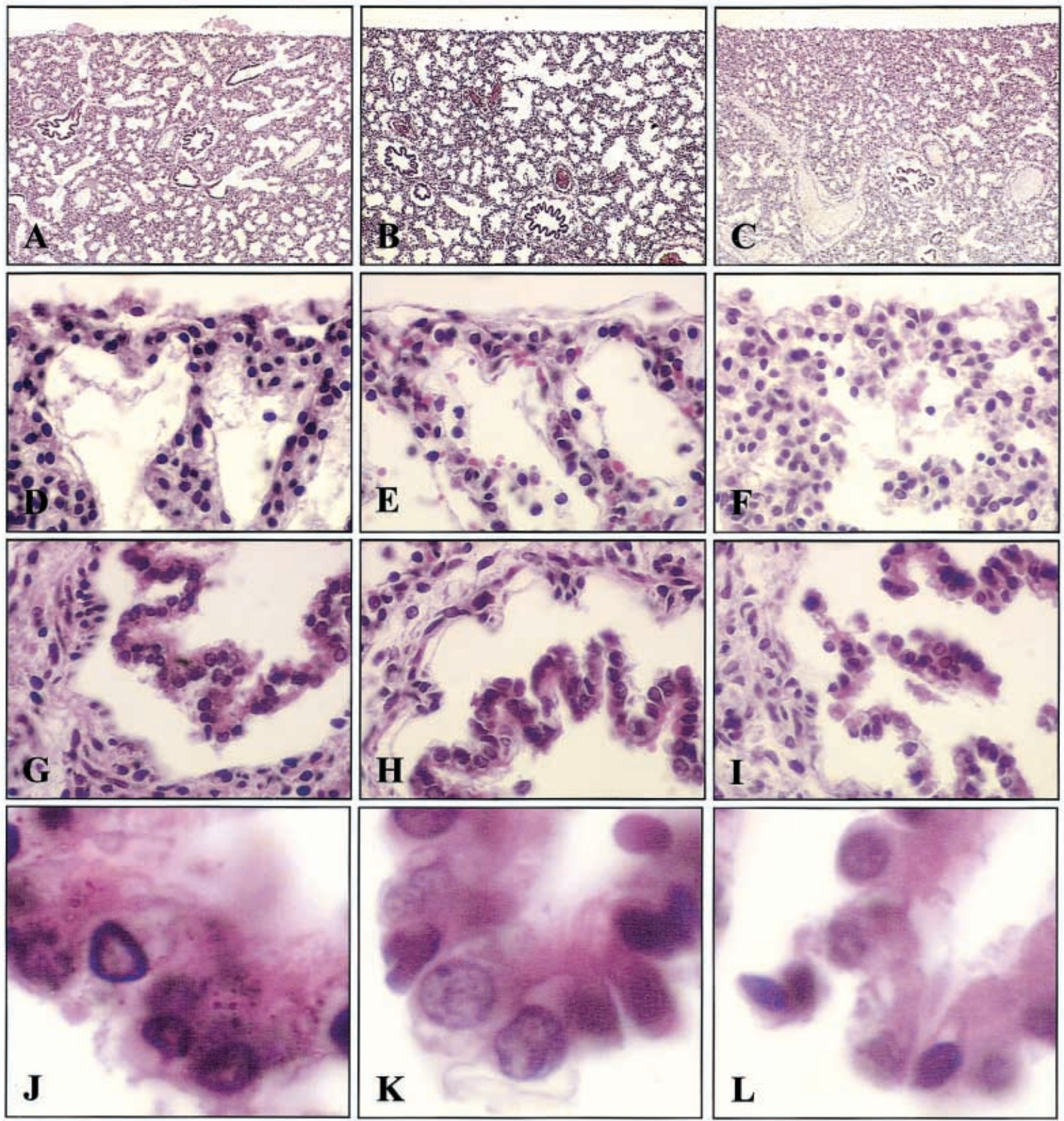

\section{U-PRL}
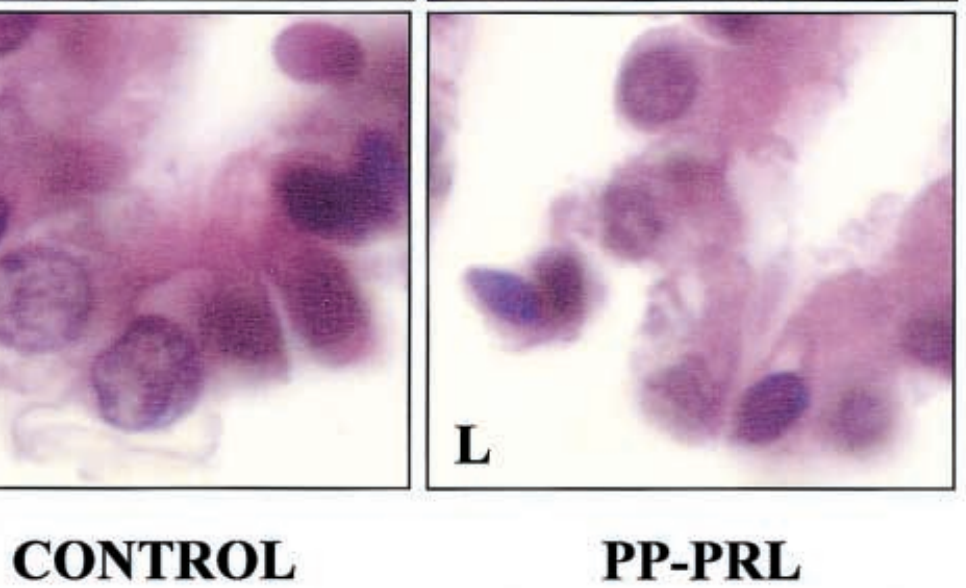

Figure 3 Histological appearance of the pup lungs in the three treatment groups. The magnification factor was 40 for A-C, 400 for D-I, and 1000 for J-L. Panels A, D, G and J are from pups exposed to U-PRL, panels B, E, H and K from control animals and panels C, F, I and L from PP-PRL-exposed pups. Note the reduction in alveolar epithelial integrity in panel $\mathrm{F}$ and bronchiolar epithelial integrity in panel I. Note the abundant intracellular particles in panel $\mathrm{J}$. 


\section{CONTROL}
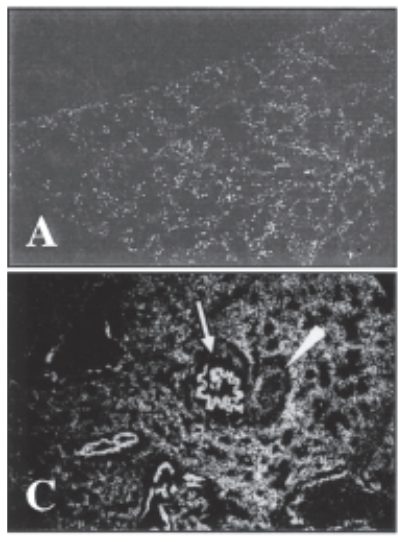

PP-PRL
U-PRL

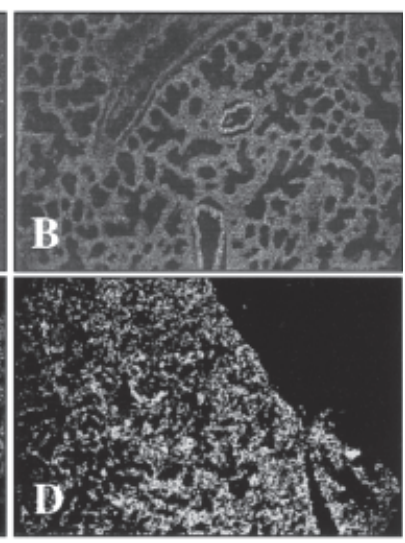

PP-PRL

Figure 4 Apoptosis in the lungs of pups in the three groups. Note the even distribution of occasional apoptotic cells in the control animals and, if any change, a reduction in this low level of apoptosis in the U-PRL-exposed pup lungs. Note also evidence of markedly increased apoptosis in the PP-PRL-exposed animals (panels C and D). Arrow denotes a bronchiole and the arrowhead, the accompanying blood vessel. Original magnification $\times 40$.

integrity is marked. In contrast, the lungs of U-PRLexposed pups showed very healthy epithelium and an accumulation of acidophilic material in the air spaces. At higher magnification, bronchiolar epithelium from the U-PRL-exposed pups showed an accumulation of intra-

cellular particles (Fig. 3J). These were not seen in any number in either the control or PP-PRL-exposed pups (Fig. 3K and L). Figure 4 shows the same tissues stained fluorescently to demonstrate apoptosis. Some apoptotic cells are present throughout the untreated pup lungs (A) and very few are present in the U-PRL-exposed lungs, although those that are seen are concentrated in bronchiolar epithelium (B). In contrast, apoptosis is marked in the PP-PRL-exposed lungs ( $C$ and $D)$.

Heart Upon gross and histological inspection, the heart of PP-PRL-exposed pups was found to have enlarged atria (Fig. 5C) and thickened ventricular walls (Fig. 5F), although heart weights were not different from those of control animals (Table 2). The thickened ventricle was evident in all serial sections examined and so was not an artifact of the plane of section. The septae and valve structures appeared normal (not shown). The appearance of the PP-PRL-exposed hearts is consistent with a developmental delay. The hearts of U-PRL-exposed pups had normal, more compact atria. Table 2 shows that the more compact U-PRL-exposed hearts weighed 33\% less than either the control or the PP-PRL-exposed hearts.

Thymus The thymus glands of PP-PRL-exposed pups were about three times the size of those of the normal control animals, and the U-PRL-exposed pup thymi were smaller than those of the control animals (Table 2). Measurement of the glands in situ proved to be a more
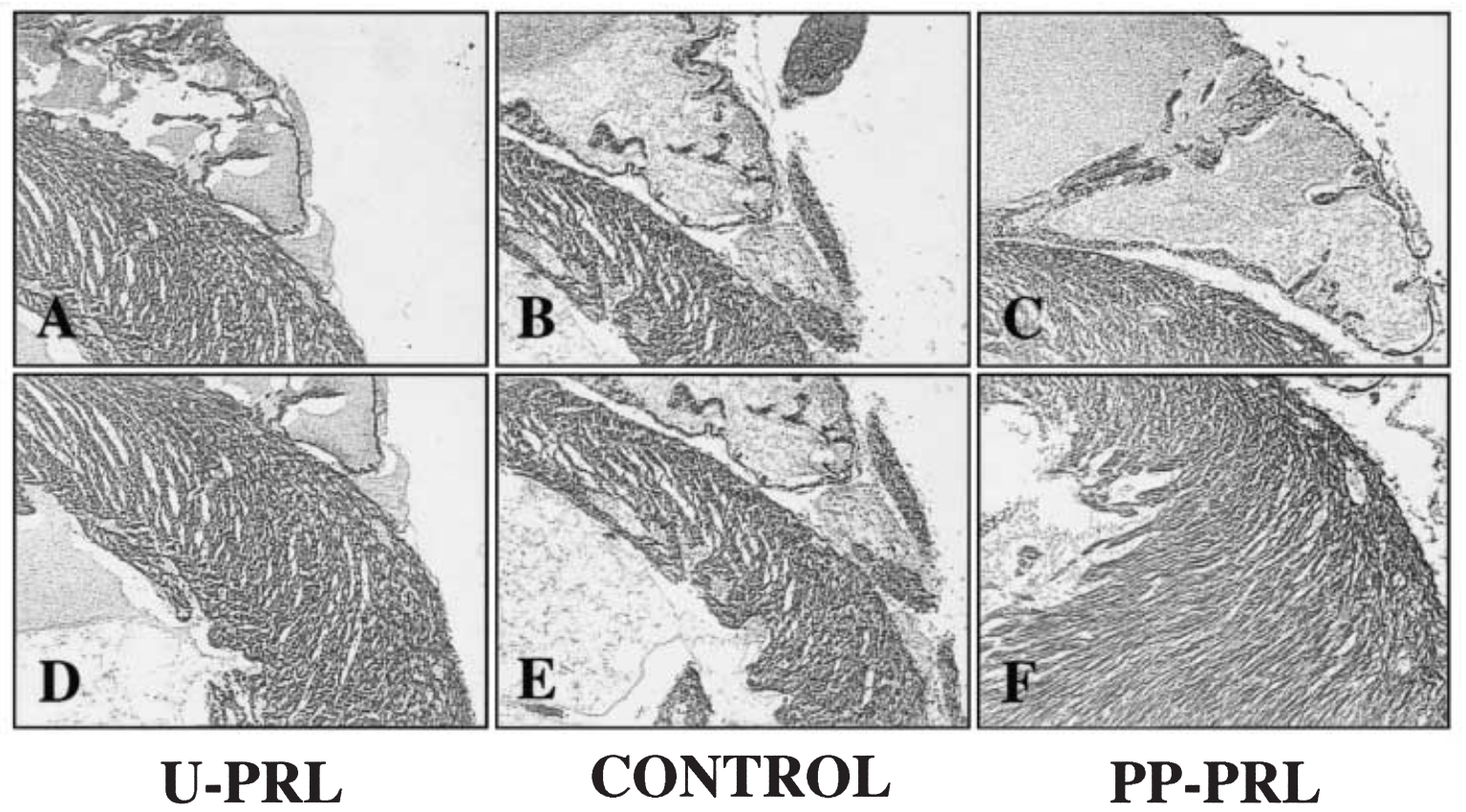

Figure 5 Histological appearance of the pup hearts in the three groups. The upper and lower panels show the same side of the heart. The atria are seen in the upper panels and a larger portion of the ventricles in the lower panels. Note the enlarged atrium and thickened ventricle in the PP-PRL-exposed animal (panels C and F). Magnification $\times 40$. 
Table 2 Effects on organs of the exposure of the pup to additional U-PRL or PP-PRL. Values are means \pm S.E.M.

\begin{tabular}{|c|c|c|c|}
\hline & Control & U-PRL-exposed & PP-PRL-exposed \\
\hline Thymus size $^{\dagger}\left(\mathrm{mm}^{2}\right)$ & $11 \cdot 27 \pm 0 \cdot 32$ & $6 \cdot 50 \pm 0 \cdot 8$ & $33 \cdot 68 \pm 0 \cdot 47$ \\
\hline Spleen weight ${ }^{\ddagger}(\mathrm{g})$ & $0 \cdot 014 \pm 0 \cdot 0018$ & $0 \cdot 014 \pm 0 \cdot 0014$ & $0 \cdot 016 \pm 0 \cdot 0015$ \\
\hline Splenocyte number $§$ & $1.73 \pm 0.21 \times 10^{6}$ & $2.76 \pm 0.19 \times 10^{6}$ & $1 \cdot 83 \pm 0.22 \times 10^{6}$ \\
\hline $\begin{array}{c}\text { Packed red cell } \\
\text { volume }(\%)\end{array}$ & $25 \pm 1 \cdot 9$ & $51 \pm 3 \cdot 2$ & $31 \pm 1 \cdot 7$ \\
\hline Heart weight* (g) & $0.045 \pm 0.006$ & $0.031 \pm 0.003$ & $0.042 \pm 0.003$ \\
\hline
\end{tabular}

${ }^{\dagger}$ Measurement of both lobes together en face. Third dimension varied between 0.89 and $1.45 \mathrm{~mm}$ in each group. $n=11$ in each group. Groups significantly different (Bonferroni $P$ value $=0 \cdot 01$ ). *Spleen weights not different. $n=11$ in each group.

${ }^{\S}$ Cells per spleen. U-PRL different from control or PP-PRL. $P<0 \cdot 001$ (repeated measures one-way ANOVA).

-Blood pooled from five pups each of four dams per group. $P<0 \cdot 01$ for control compared with U-PRL and for PP-PRL compared with U-PRL (Bonferroni correction). No statistically significant difference between control and PP-PRL.

${ }^{*}$ Heart and content weight. $n=11$ in each group. $P=0.03$ for control compared with U-PRL; $P=0 \cdot 04$ for PP-PRL compared with U-PRL. No difference between control and PP-PRL.

representative parameter of change than cellularity, because of the fragile nature of the thymocytes in the PP-PRL-exposed group. On histological examination, the control thymi showed a normal, very clear distinction between the cortex and medulla (Fig. 6B). This distinction was obscured in the PP-PRL-exposed thymus glands by the presence of a very large number of apoptotic thymocytes in the medulla (Fig. 6C and F). The U-PRLexposed thymi appeared relatively normal, although there were fewer thymocytes and a greater proportion of the thymocytes were large and euchromatic (Fig. 6D). Some of these were present in the medulla, producing slightly less distinct cortico-medullary junctions (Fig. 6A) than were evident in the controls.

Spleen The spleens of the U-PRL and PP-PRLexposed pups were of normal weight (Table 2). Histological examination and direct cell counting showed the control and PP-PRL-exposed spleens to contain comparable numbers of cells (Fig. 6H and I, Table 2). In contrast, spleens exposed to U-PRL contained a much larger number of cells (Fig. 6G and J).

Blood Pups from U-PRL-treated dams had a larger number of mature red blood cells in the circulation, as illustrated by both the packed red cell volume and the decreased number of normoblasts compared with controls (Tables 2 and 3). The absolute number of nucleated blood cells was about half that seen in either the control or PP-PRL-exposed pups, illustrating a shift towards erythropoiesis in response to U-PRL exposure. When each white blood cell type was expressed as a percentage of white blood cells present, it was evident that general myeloid development was favored at the expense of lymphoid development in the U-PRL-exposed pups. In comparison, exposure to PP-PRL had only relatively minor hematopoietic effects, promoting red blood cell maturation and producing an increased number of granulocytes.

Brown fat Both U-PRL-exposed and PP-PRL-exposed pups showed a change in brown fat (Fig. 7). The PP-PRLexposed pups had brown fat cells with reduced numbers of lipid droplets compared with the control animals. The U-PRL-exposed pups had brown fat cells with no lipid droplets visible at the light microscope level. Changes in the lipid droplet content were not correlated with the presence or absence of milk in the stomach of the pups. They were not, therefore, changes subsequent to feeding.

\section{Maternal progesterone}

Treatment with either form of recombinant PRL had no effect on progesterone concentrations on day 6.5 of pregnancy/pseudopregnancy (Table 1). This was an important consideration, because PRL increases progesterone production by blocking its conversion to an inactive derivative, via 20a-hydroxysteroid dehydrogenase (Zhong et al. 1997).

\section{Discussion}

Administration of the molecular mimic of phosphorylated PRL, PP-PRL, resulted in histologically obvious changes in a number of important tissues. Administration of the wild-type recombinant hormone, which is equivalent to unmodified hormone, did not have the same effects. As both PRLs were produced under exactly the same conditions, it is unlikely that the observed effects in these tissues were due to some non-specific contaminant of the preparations. Furthermore, in several instances the 

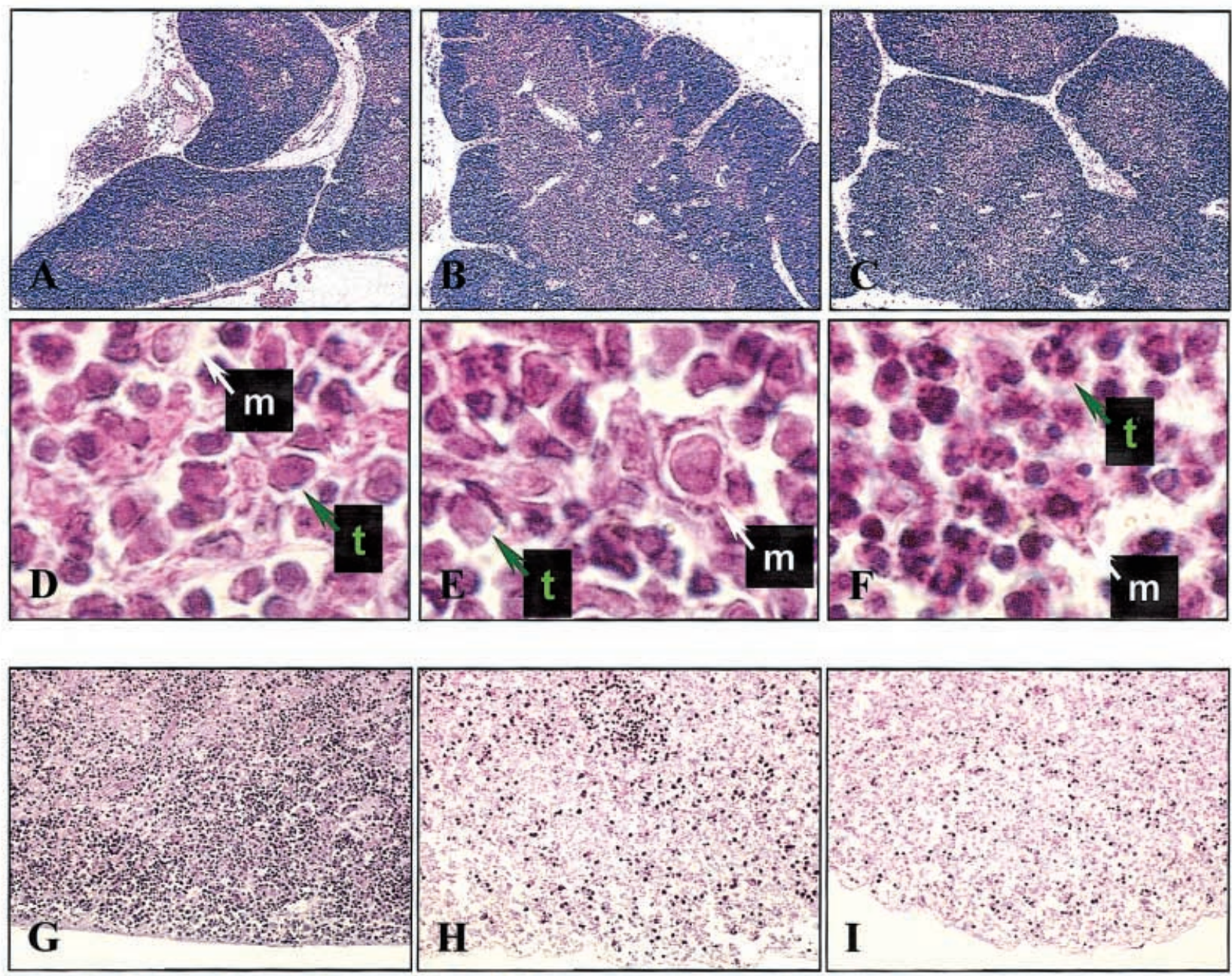

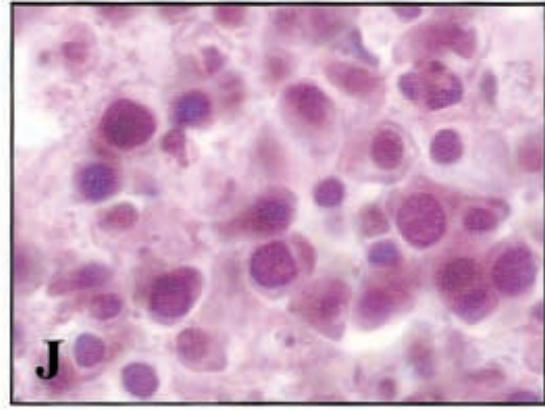

U-PRL

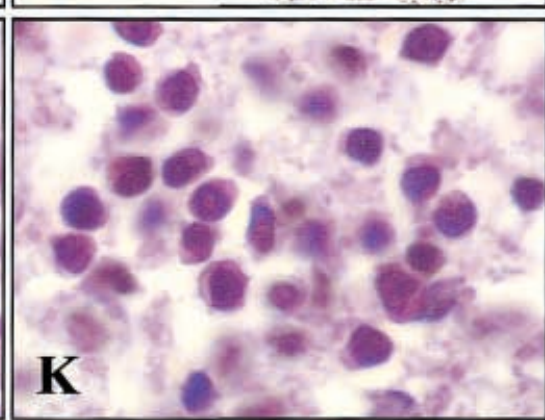

CONTROL

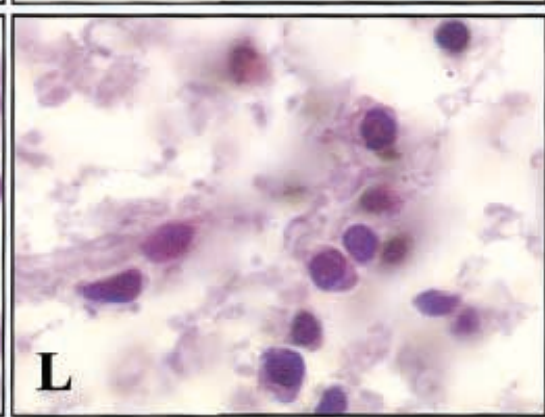

PP-PRL

Figure 6 Pup thymic and splenic histology. Panels A-F are thymus, and panels $\mathrm{G}-\mathrm{L}$ are spleen. The magnification factor for panels A-C and $\mathrm{G}-\mathrm{I}$ was 40 and that for panels D-F and $\mathrm{J}-\mathrm{L}$ was 1000 . Panels D-F are of the thymic medullary region. Note the abundant apoptotic thymocytes in panel F. Note the increased cellularity of the spleens from U-PRL-exposed pups (panels G and J). m, macrophage; $t$, thymocyte. 
Table 3 Differential blood count of pups exposed to additional U-PRL or PP-PRL. The numbers are the mean \pm S.E.M. of four smears derived from pups from different dams. Each smear was made from blood pooled from five pups

\begin{tabular}{|c|c|c|c|c|c|c|c|c|}
\hline & Neutrophils & Lymphocytes & Monocytes & Eosinophils & Basophils & Blasts & Total nucleated & Total WBC \\
\hline \multicolumn{9}{|l|}{ Numbers } \\
\hline Control & $51 \pm 3$ & $68 \pm 2 \cdot 9$ & $10 \pm 0 \cdot 6$ & 1 & 0 & $89 \pm 4^{*}$ & $219 \pm 11$ & $130 \pm 9$ \\
\hline U-PRL & $55 \pm 3$ & $7 \pm 0 \cdot 8$ & $16 \pm 0 \cdot 6$ & 0 & 0 & $32 \pm 1$ & $110 \pm 7$ & $78 \pm 6$ \\
\hline PP-PRL & $78 \pm 2$ & $60 \pm 3$ & $20 \pm 1$ & $6 \pm 0 \cdot 4$ & 1 & $32 \pm 1 \cdot 1$ & $196 \pm 12$ & $164 \pm 10$ \\
\hline \multicolumn{9}{|c|}{ As percentage of WBC } \\
\hline Control & $39 \cdot 2$ & 52 & $7 \cdot 7$ & $0 \cdot 77$ & & & & \\
\hline U-PRL & 70 & 9 & $20 \cdot 5$ & 0 & & & & \\
\hline PP-PRL & $47 \cdot 6$ & $36 \cdot 6$ & $12 \cdot 2$ & $3 \cdot 6$ & & & & \\
\hline
\end{tabular}

*Mostly normoblasts; WBC, white blood count.

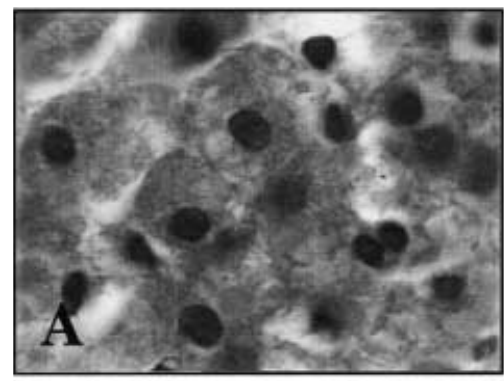

U-PRL

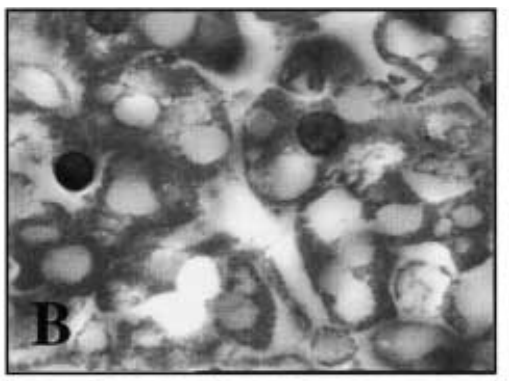

CONTROL

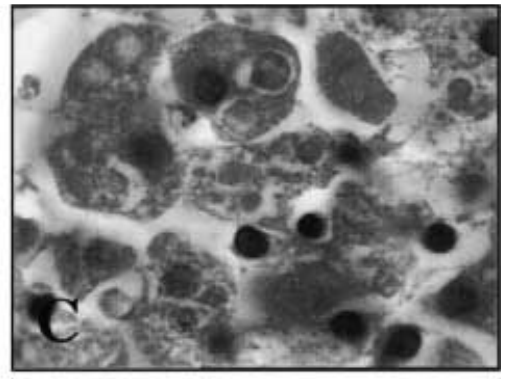

PP-PRL

Figure 7 Pup brown fat. Magnification $\times 1000$. Note the large lipid droplets in the cells from the control animals $(B)$. The number of lipid droplets is reduced in animals exposed to PP-PRL $(C)$ and no droplets are visible in the tissue derived from U-PRL-exposed animals (A).

opposite result was obtained with wild-type (U-PRL) and the mimic of phosphorylated PRL. This supports the specificity of the observed effects. In addition, in tissues in which opposite effects occurred, it was apparent that the effects were not due to a change in the absolute amount of PRL, but to the ratio between the two forms of PRL.

As both short- and longer-term clearance were the same for both PRLs, the differential effects of these two PRLs cannot be attributed to different half-lives in the serum.

Although PP-PRL has been shown to be a U-PRLmediated growth antagonist (Ho et al. 1989, Wang \& Walker 1993, Chen et al. 1998, Krown et al. 1992), the effects of PRL in the ovary are not growth related. Lack of antagonism in the production of progesterone was therefore not entirely unexpected. Progesterone concentrations were the same in control animals and animals receiving either U-PRL or PP-PRL. This was first discovered in early experiments in which some animals were also given progesterone, in case it was necessary in order to achieve pregnancy. As there was no effect on progesterone concentrations, we know that the effects on pup tissues were not secondary to altered progesterone concentrations.

Progesterone is required for the production of a pseudopregnant state, necessary for successful blastocyst implantation. With $6 \mu \mathrm{g} / 24 \mathrm{~h}$, the number of implantation sites was indistinguishable among the groups (Table 1), corre- lating well with the progesterone results. The Alzet minipump was implanted at day 0.5 and it takes about 3 days for circulating concentrations of the recombinant proteins to stabilize; steady concentrations would therefore have been present at the time of implantation. Failure of blastocyst implantation is common to both the PRL and PRL receptor knockout animals (Horseman et al. 1997, Ormandy et al. 1997) and it has been suggested, therefore, that PRL is necessary for implantation. The knockout animals, however, also have reduced progesterone in response to mating, and are unable to achieve a state of pseudopregnancy. Our model has unaltered progesterone and suggests that neither an increase in total PRL nor a change in ratio of PRL forms alters implantation. This experiment, however, could not examine the requirement for PRL, as PP-PRL did not act as an antagonist to implantation.

Administration of PP-PRL at $6 \mu \mathrm{g} / 24 \mathrm{~h}$ had a sufficiently significant effect on $27 \%$ of pups to cause resorption or stillbirth or death within $8 \mathrm{~h}$ of birth. Whether this was due to a greater degree of the described pup pathologies or placental/decidual pathologies is unknown at present. By far the majority of pups survived, however, and it was only those pups that were examined further. This set of experiments did not examine the long-term survival of PP-PRL-exposed pups, because we 
were specifically interested in examining developmental effects. Longer-term studies would be complicated by the need to foster the pups, because PP-PRL administration severely affected mammary gland development in the mothers (data not shown). The PP-PRL-treated mothers also showed evidence of abnormal maternal behavior, which would also adversely affect pup survival. Effects of PP-PRL on maternal behavior are currently under investigation through appropriate collaboration.

A role for PRL in lung development has been discussed for some time (Hamosh \& Hamosh 1977, Gluckman et al. 1978, Hauth et al. 1978, Oguchi et al. 1994). Most of the work has considered the possibility that PRL promotes the production of surfactant. Thus, in human premature infants, cord blood PRL concentrations (Haugh et al. 1978) and amniotic fluid PRL (Gluckman et al. 1978) can be correlated with fetal lung maturation and augmented surfactant formation. In fetal rabbits, fetal intramuscular injection of PRL increased surfactant production in utero (Hamosh \& Hamosh 1977), and in bullfrogs anti-PRL antisera decreased surfactant production during metamorphosis (Oguchi et al. 1994). The loss of epithelial integrity seen in the lungs of PP-PRL-exposed pups would certainly be consistent with decreased or absent surfactant production. In the absence of surfactant, some epithelial damage could result from attempts to inflate alveoli. The reason for greater damage in the left lung is unclear, but the smaller size observed at postmortem could be the result of complete lack of inflation, again a possible sequela of abnormal surfactant production. Increased intracellular inclusions in bronchiolar epithelium would be consistent with U-PRL promotion of surfactant production, as would the presence of acidophilic material within the air spaces. An alternate explanation is that U-PRL is an important survival factor for epithelial cells. Indeed, exposure to U-PRL decreased, and exposure to PP-PRL increased, the number of apoptotic cells throughout the lung. This regulation of apoptosis by PRL in the lung has not been reported previously. We suggest that only healthy epithelial cells would be engaged in surfactant production and, hence, that effects on surfactant are secondary to those on cell viability. These effects of PRL in the maturation of the lung are consistent with the presence of PRL receptors on bronchiolar epithelial cells in the fetal rat several days before birth (Royster et al. 1995, Freemark et al. 1997). At earlier times, however, PRL receptors are found on lung stromal cells (Freemark et al. 1997), suggesting perhaps additional roles for PRL in lung development-additional effects that may contribute to the severity of the pathology in the left lobe. In the rat, lung development on the left and the right sides is very different (Hebel \& Stromberg 1986).

PRL receptors have also been localized to cardiac muscle, certainly by day 18.5 of gestation in the rat (Royster et al. 1995, Tzeng \& Linzer 1997). Administration of PP-PRL resulted in the birth of animals in which the heart morphology resembled that of 18.5 day old fetuses (Hebel \& Stromberg 1986). Because of the growth-antagonistic properties of the two PRLs, this implies an important role for U-PRL in the final tissue reorganization within the heart. This reorganization includes a reduction in atrial volume and a reduction/ compaction in the ventricular wall (Hebel \& Stromberg 1986) - processes that were promoted by U-PRL. Clearly, however, these apparent developmental delays caused by exposure to PP-PRL were consistent with viability after birth, and perhaps would not have been obvious if we had examined the pups at a later stage.

Fetal thymocytes also express the PRL receptor (Freemark et al. 1995, Royster et al. 1995, Brown-Borg et al. 1996). In the PP-PRL-exposed pups, the thymus contained abundant apoptotic thymocytes. The number was so large that they spilled over into the medulla, thereby obscuring the cortico-medullary junction. An increase in the number of apoptotic cells in the thymus could be due to antagonism between U-PRL and PPPRL and indicate an important role for U-PRL in T cell survival during maturation and selection, or in recruitment of macrophages required for the disposal of apoptotic cells. In regard to the latter suggestion, however, both U-PRL and PP-PRL increased circulating monocytes, and hence there should have been no shortage of macrophage precursors in the PP-PRL-exposed pups. The PP-PRLexposed thymi were larger, at least in part because of the necessity to hold the large number of apoptotic cells, which cannot pass out into the peripheral circulation. The U-PRL-exposed thymi were smaller than those in the control animals, suggesting efficient maturation and movement of mature thymocytes out into the peripheral circulation, reduced seeding from the bone marrow, efficient macrophage disposal of apoptotic cells, or combinations of these. The reduced number of lymphocytes in the circulation suggests that lower seeding in part explains the smaller thymus, but the antagonist effects of U-PRL and PP-PRL and the increased apoptosis on exposure to PP-PRL also suggests that U-PRL promotes the survival and maturation, and therefore exit, of cells. The thymic size results are in general agreement with those of previous reports from three other groups. Treatment with anti-PRL antiserum increased cellularity in the thymus of newborn mice (Russell et al. 1988) and treatment with PRL depressed thymocyte cellularity in Snell dwarf mice (Murphy et al. 1993). In addition, observation of PRL knockout mice showed increased cellularity in the thymus compared with that in heterozygous littermates, even at 6 weeks of age (Horseman et al. 1997) after exposure to PRL via the milk of foster mothers (Kacsoh et al. 1993). Our study is the only one, however, to have noted that a significant proportion of the increased number of cells in the thymus were apoptotic. This casts a very different interpretation on the results. Our results would be best explained by PRL promoting intrathymic cell survival. A 
survival role for PRL has been well established in $\mathrm{Nb} 2 \mathrm{~T}$ lymphoma cells (Witorsch et al. 1993, Leff et al. 1996). The small size of the thymus is therefore likely to be a consequence of both reduced seeding and the efficient maturation and exit of cells that do make it.

The spleen is a site of hematopoiesis during embryonic development and for a short while after birth. The spleens of the no-PRL and the PP-PRL-exposed pups were indistinguishable, but the spleens of the U-PRL-exposed pups had an increased number of cells as determined both by counting those expressed from the organ and histological observation. Given the increase in erythropoiesis in these animals, many of these cells are likely to be erythroid precursors - a suggestion consistent with their morphology. An increase in erythropoiesis in response to PRL is consistent with the findings of studies in which PRL was administered to mature mice (Woody et al. 1999) and work analyzing bone marrow stromal production of PRL (Bellone et al. 1997). Our work, however, is the first to show distinct effects of the two forms of PRL, effects in rats and effects on the developing hematopoietic system. As U-PRL stimulated erythropoiesis at the expense of lymphopoiesis, it appears that U-PRL exerts its effect on an early pluripotential stem cell. PP-PRL, in contrast, had no negative impact on lymphopoiesis, but promoted granulocyte production and normoblast maturation.

Large numbers of PRL receptors have been observed in brown fat in late-stage fetal rats (Royster et al. 1995). It was expected, therefore, that administration of U-PRL or PP-PRL, or both, would have significant effects on this tissue, and such was the case. Unlike most of the other tissues, however, exposure of brown fat to U-PRL or PP-PRL showed differing degrees of the same effect. PP-PRL exposure reduced visible lipid droplets, and U-PRL exposure eliminated visible lipid droplets. Thus in this tissue in which the effects of PRL may be nonproliferative (Nedergaard et al. 1986), as is the case in the ovary, PP-PRL did not function as an antagonist to UPRL. These effects of the two forms of PRL in brown fat were initially unexpected because, in the lung and mammary gland, PRL promotes lipid synthesis (Hauth et al. 1978, Hallowes et al. 1973). Our finding, however, may simply indicate increased exposure to PRL. Thermogenic output from brown fat decreases lipid content and there are correlative associations between PRL exposure and brown fat thermogenic activity in rodent pups (Nedergaard et al. 1986), although the opposite effect seems to occur in the dams (Chan \& Swaminathan 1990).

This is the first study to have produced real histological clues as to the role of PRL in most of these fetal tissues. The histologically described abnormalities observed were consistent with viability, at least for a few hours. In $27 \%$ of pups, however, the abnormalities resulted in death. Whether consistent alterations in tissue morphology will be observed in the PRL and PRL receptor knockout animals remains to be determined. The histological appearance of very few tissues has been reported for these knockout animals (Horseman et al. 1997, Ormandy et al. 1997, Clement-Lacroix et al. 1999) and most data emerging so far have been derived from much older animals (Horseman et al. 1997, Ormandy et al. 1997).

The results of the current study clearly demonstrate the importance of maternal circulating PRL during rodent pregnancy, in addition to the importance of the relative ratios of U-PRL to PP-PRL. The importance of maternal circulating PRL with regard to fetal tissue development was unexpected, because it is widely believed that the ligand for fetal PRL receptors is either amniotic fluid PRL (reviewed in Ben-Jonathan et al. 1996) or placental lactogens (Freemark et al. 1993). The various mechanisms by which maternal circulating PRL could override the excess quantities of either amniotic fluid PRL or placental lactogens are currently the subject of continued investigation.

\section{Acknowledgements}

Grant sponsor USDA; Grant number 9703543. This work was also supported by Sensus Corporation (Austin, TX, USA), and a generous gift from Bill and Charis Bennett. The authors thank Ms Nancy Price for preparation of the manuscript, and Ms Sally Scott for dedicated assistance with animal husbandry.

\section{References}

Aramburo C, Monteil JL, Proudman JA, Berghman LR \& Scanes CG 1992 Phosphorylation of prolactin and growth hormone. Journal of Molecular Endocrinology 8 183-191.

Bellone G, Astarita P, Artusio E, Silvestri S, Mareschi K, Turletti A, Buttiglieri S, Emanuelli G \& Matera L 1997 Bone marrow stromaderived prolactin is involved in basal and platelet-activating factor-stimulated in vitro erythropoiesis. Blood 90 21-27.

Ben-Jonathan N, Mershon JL, Allen DL \& Steinmetz RW 1996 Extrapituitary prolactin: distribution, regulation, functions, and clinical aspects. Endocrine Review 17 639-668.

Brooks CL, Kim BG, Aphale P, Kleeman BE \& Johnson GC 1990 Phosphorylated variant of bovine prolactin. Molecular and Cellular Endocrinology 71 117-123.

Brown-Borg HM, Zhang FP, Huhtaniemi I \& Bartke A 1996 Developmental aspects of prolactin receptor gene expression in fetal and neonatal mice. European Journal of Endocrinology 134 751-757.

Chan E \& Swaminathan R 1990 Role of prolactin in lactationinduced changes in brown adipose tissue. American Journal of Physiology 258 R51-R56.

Chen TJ, Kuo CYB, Tsai KF, Liu JW, Chen DY \& Walker AM 1998 Development of recombinant human prolactin receptor antagonists by molecular mimicry of the phosphorylated hormone. Endocrinology 139 609-616.

Clapp C 1987 Analysis of the proteolytic cleavage of prolactin by the mammary gland and liver of the rat: characterization of the cleaved and 16K forms. Endocrinology 121 2055-2064.

Clement-Lacroix P, Ormandy C, Lepescheux L, Ammann P, Damotte D, Goffin V, Bouchard B, Amling M, Gaillard-Kelly M, Binart N, Baron R \& Kelly PA 1999 Osteoblasts are a new target for prolactin: analysis of bone formation in prolactin receptor knockout mice. Endocrinology 140 96-105. 
Freemark M, Kirk K, Pihoker C, Robertson M, Shiu R \& Driscoll P 1993 Pregnancy lactogens in the rat conceptus and fetus: circulating levels, distribution of binding and expression of receptor messenger RNA. Endocrinology 133 1830-1842.

Freemark M, Nagano M, Edery M \& Kelly PA 1995 Prolactin receptor gene expression in the fetal rat. Journal of Endocrinology 144 285-292.

Freemark M, Driscoll P, Maaskant R, Petryk A \& Kelly PA 1997 Ontogenesis of prolactin receptors in the human fetus in early gestation. Implications for tissue differentiation and development. Journal of Clinical Investigation 99 1107-1117.

Gluckman PD, Ballard PL, Kaplan SL, Liggins GC \& Grumbach MM 1978 Prolactin in umbilical cord blood and the respiratory distress syndrome. Journal of Pediatrics 93 1011-1014.

Greenan JR, Balden E, Ho TWC \& Walker AM 1989 Biosynthesis of the secreted $24 \mathrm{Kd}$ isoforms of prolactin. Endocrinology $\mathbf{1 2 5}$ 2041-2048.

Hallowes RC, Wang DY, Lewis DJ, Strong CR \& DilsR 1973 The stimulation by prolactin and growth hormone of fatty acid synthesis in explants from rat mammary glands. Journal of Endocrinology $5 \mathbf{7}$ 265-276.

Hamosh M \& Hamosh P 1977 The effect of prolactin on the lecithin content of fetal rabbit lung. Journal of Clinical Investigation 59 1002-1005.

Hauth JC, Parker CR, MacDonald PC, Porter JC \& Johnston JM 1978 A role of fetal prolactin in lung maturation. Obstetrics and Gynecology 51 81-88.

Hebel R \& Stromberg MW 1986 Embryology. In Anatomy and Embryology of the Laboratory Rat, pp 231-257. Eds R Hebel \& MW Stromberg. Günzburg, Federal Republic of Germany: Biomed Verlag.

Ho TWC, Greenan JR \& Walker AM 1989 Mammotroph autoregulation: the differential roles of the isoforms of prolactin. Endocrinology 124 1507-1514.

Ho TWC, Kawaminami M \& Walker AM 1993a Secretion of phosphorylated and non-phosphorylated monomer prolactin isoforms during rat pregnancy and pseudopregnancy. Endocrine Journal 1 435-439.

Ho TWC, Leong FS, Olaso CH \& Walker AM $1993 b$ Secretion of specific non-phosphorylated and phosphorylated rat prolactin isoforms at different stages of the estrous cycle. Neuroendocrinology $\mathbf{5 8}$ 160-165.

Horseman ND, Zhao W, Montecino-Rodriguez E, Tanaka M, Nakashima K, Engle SJ, Smith F, Markoff E \& Dorshkind K 1997 Defective mammopoiesis, but normal hematopoiesis, in mice with a targeted disruption of the prolactin gene. EMBO Journal 16 6926-6935.

Kacsoh B, Veress Z, Toth BE, Avery LM \& Grosvenor CE 1993 Bioactive and immunoreactive variants of prolactin in milk and serum of lactating rats and their pups. Journal of Endocrinology 138 243-257.

Krown KA, Wang YF, Ho TWC, Kelly PA \& Walker AM 1992 Prolactin isoform 2 as an autocrine growth factor for GH3 cells. Endocrinology 131 595-602.

Kuo CB, Chen C, Xu X, Yang L, Liu Y, Coss D \& Walker AM 2000 Unmodified prolactin promotes ductal and lobulo-alveolar growth, while a molecular mimic of phosphorylated prolactin promotes lobuloalveolus formation and casein gene expression in the pregnant rat mammary gland. Proceedings of the Endocrine Society, 82nd Annual Meeting. Toronto, Canada. Abstract 791.

Leff MA, Buckley DJ, Krumenacker JS, Reed JC, Miyashita T \& Buckley AR 1996 Rapid modulation of the apoptosis regulatory genes, bcl-2 and bax by prolactin in rat $\mathrm{Nb} 2$ lymphoma cells. Endocrinology 137 5456-5462.

Lewis UJ, Singh RMP, Lewis LJ, Seavey BK \& Sinha YN 1984 Glycosylated ovine prolactin. PNAS 81 385-389.
McLean IW \& Nakane PK 1974 Periodate-lysine-paraformaldehyde fixative. A new fixation for immunoelectron microscopy. Journal of Histochemistry and Cytochemistry 22 1077-1083.

Murphy WJ, Durum SK \& Longo DL 1993 Differential effects of growth hormone and prolactin on murine $\mathrm{T}$ cell development and function. Journal of Experimental Medicine 178 231-236.

Nedergaard J, Connolly E \& Cannon B 1986 Brown adipose tissue in the mammalian neonate. In Brown Adipose Tissue, ch 7, pp 152-213. Eds P Trayhurn \& DG Nicholls. London: Edward Arnold.

Oetting WS \& Walker AM 1985 Intracellular processing of prolactin. Endocrinology 117 1565-1570.

Oetting WS, Tuazon PT, Traugh JA \& Walker AM 1986 Phosphorylation of prolactin. Journal of Biological Chemistry 261 1649-1652.

Oguchi A, Mita M, Ohkawa M, Kawamura K \& Kikuyama S 1994 Analysis of lung surfactant in the metamorphosing bullfrog Crana catesbeinia. Journal of Experimental Zoology 269 515-521.

Ormandy CJ, Camus A, Barra J, Damotte D, Lucas B, Buteau H, Edery M, Brousse N, Babinet C, Binart N \& Kelly PA 1997 Null mutation of the prolactin receptor gene produces multiple reproductive defects in the mouse. Genes and Development 11 167-178.

Royster M, Driscoll P, Kelly PA \& Freemark M 1995 The prolactin receptor in the fetal rat: cellular localization of messenger ribonucleic acid, immunoreactive protein, and ligand-binding activity and induction of expression in late gestation. Endocrinology 136 3892-3900.

Russell DH, Mills KT, Talamantes FJ \& Bern HA 1988 Neonatal administration of prolactin antiserum alters the developmental pattern of T- and B-lymphocytes in the thymus and spleen of BALB/c female mice. PNAS 85 7404-7407.

Sinha YN 1995 Structural variants of prolactin: occurrence and physiological significance. Endocrine Review 16 354-369.

Sinha YN, Gilligan TA, Lee DW, Hollingsworth D \& Markoff E 1985 Cleaved prolactin: evidence for its occurrence in human pituitary gland and plasma. Journal of Clinical Endocrinology and Metabolism 60 239-242.

Tzeng SJ \& Linzer DIH 1997 Prolactin receptor expression in the developing mouse embryo. Molecular Reproduction and Development 48 45-52.

Wang YF \& Walker AM 1993 Dephosphorylation of standard prolactin produces a more biologically active molecule. Evidence for antagonism between non-phosphorylated and phosphorylated prolactin in the stimulation of $\mathrm{Nb} 2$ cell proliferation. Endocrinology 133 2156-2160.

Wang YF, Liu JW, Mamidi M \& Walker AM 1996 Identification of the major site of rat prolactin phosphorylation as serine 177. Journal of Biological Chemistry 271 2462-2469.

Witorsch RJ, Day EB, LaVoie HA, Hashemi N \& Taylor JK 1993 Comparison of glucocorticoid-induced effects in prolactindependent and autonomous rat $\mathrm{Nb} 2$ lymphoma cells. Proceedings of the Society for Experimental Biology and Medicine 203 454-460.

Woody MA, Welniak LA, Sun R, Tian ZG, Henry M, Richards S, Raziuddin A, Longo DL \& Murphy WJ 1999 Prolactin exerts hematopoietic growth-promoting effects in vivo and partially counteracts myelosuppression by azidothymidine. Experimental Hematology 27 811-816.

Zhong L, Parmer TG, Robertson MC \& Gibori G 1997 Prolactin mediated inhibition of $20 \alpha$-hydroxysteroid dehydrogenase gene expression and the tyrosine kinase system. Biochemical and Biophysical Research Communications 235 587-592.

Received 4 August 2000

Accepted 28 September 2000 